\title{
Strategic HR in Higher Educational Institutions in Malaysia and Denmark
}

\author{
Azlineer Sarip and Mohamad Abdillah Royo
}

\begin{abstract}
The objective of this paper is to explore the strategic roles of $\mathrm{HR}$ professionals at Higher Educational Institutions (HEIs) in Malaysia and Denmark and to investigate the factors that influence the differences between the Human Resource (HR) departments in the two countries. This research uses case study approach. Semi-structured interviews were conducted with different levels of HR professionals in the HR department, namely HR directors, HR managers and HR officers. The results show that the centralization or decentralization of HR functions does have an impact on how the HR department in the organization fulfils its role.
\end{abstract}

Index Terms-HR strategic role, human resource management, higher educational institutions, decentralization of $\mathrm{HR}$ functions.

\section{INTRODUCTION}

The subject of HR wearing the hat of a strategic player in the organization has been discussed for more than two decades. An extensive literature has discussed the evolution of HR field. Many of the empirical works, however, took place in the private sector. This is probably because the fast changing market in the private sector makes the discussion of $\mathrm{HR}$ in the sector more intriguing to researchers.

This study, however, focuses on HR departments in HEIs. Education has become a new emerging business, especially in countries like Australia, Canada, the US and the UK. Stiff competition among the universities and their aim to achieve top positions among the world ranking universities make the management of human resources in universities just as challenging as it is in private sector. The internationalization and globalization of universities create new challenges for universities and for their HR departments.

The objective of this study is to explore the roles of HR departments in HEIs in Malaysia and Denmark. In addition, the study examines the challenges faced by HR departments in HEIs in fulfilling these roles. The next section of this paper will discuss different opinion on how HR professionals should play their roles and what is needed for them to fulfill these roles. This is followed by an outline of the methods that were used to conduct this study. The later part of the paper discusses the findings and closes with conclusions.

Manuscript received July 19, 2013; revised October 31, 2013

Azlineer Sarip is with the Faculty of Management, Universiti Teknologi Malaysia, 81310 UTM Skudai Johor, Malaysia (e-mail: azlineer@ utm.my).

Mohamad Abdillah Royo is with the Faculty of Education, Universiti Teknologi Malaysia, 81310 UTM Skudai Johor, Malaysia (e-mail: abdillah@utm.my).

\section{LITERATURE REVIEW}

The evolution of the HR function is normally seen as a development from HR simply being the personnel function to it becoming a strategic partner to the organization. Dulebohn et al. [1], Jamrog and Overholt [2] were able to trace the history of the personnel department to as early as 1900, when according to Dulebohn et al. [1], companies started to hire someone to manage the welfare of the employees. Jamrog and Overhalt [2] however added that the first HR department was only established in 1920. The discussion continues about how HR personnel moved from just handling the files of the employees to proper HR functions such as job scope, etc. Strategic issues in HR did not become a topic of discussion for practioners and academicians until the mid-1990s [3].

Researchers came up with various reasons why the HR department had to develop from just being the file clerk to becoming a strategic partner to the organization. Yeung and Brockbank [4] for example said that "...pressures to reduce costs, higher expectation of customers, the constant drive to meet global competitive challenges, and opportunities offered by advancement in information technology" (p. 1) are among the factors that contributed to the development of HR functions. Researchers such as Ehrlich [5] believe that transformation was required because the performance of an organization basically depended on whether its employees were treated well. More recently, Tyson [6] argues that HR had to change because of the need for it to be a strategic partner to the organization, advancements in technology which have changed the way the HR function is delivered, and also opportunities to outsource the administrative HR function. Yeung et al. [7] added, "HR professionals have no choice but to transform HR activities from administrative and operational orientations to business and strategic focus, or face the risk of being replaced or outsourced" (p.6). Finally, according to Mothershell et al. [8], HR is now expected to focus on the needs of the business, the employees and the line managers.

Due to the expected changes in the HR function, those who follow the literature on the HR field can see how the role of HR has transformed from personnel to strategic human resource management. Discussions about the HR role were mainly based on Ulrich's concept of multiple HR roles. A vast number of researchers in this area such as Beatty and Schneier [10], Brockbank [11], Buyens and De Vos [12], Langbert and Friedman [13], Truss [14], Marler [15] and many more used Ulrich's model in their discussions. According to Ulrich [9], there are four key HR roles, namely administrative expert, employee champion, change agent and strategic partner. The role of administrative expert focuses 
more on the administrative side, for example improving work processes, reducing operational costs, and increasing efficiency. According to Ulrich, this is the role of most HR departments. The employee champion role is where HR is expected to be an intermediary between the management and the employees in the organization. This role requires the HR department to balance the needs of the organization with those of the employees. Therefore according to Ulrich, this role is critical because the commitment of the employees very much depends on whether their needs are being met. The third role is change agent, in which HR is expected to facilitate change in the organization. Although they are only expected to facilitate the change process, it is nevertheless a difficult role to fulfill. According to Ulrich, "being a change agent is clearly part of the value-added role of HR professionals as business partners" [9] (p.31). Finally yet importantly, there is the strategic partner role. As strategic partners, HR departments are expected to assist their organization in achieving its targets. HR departments must able to translate the organization's objectives into policies and activities that help to achieve those targets. Truss [14] views this role as one that requires the HR department to be involved strategically through the integration of HR planning with the planning of the organization, through its involvement in decision making in the organization, and through helping the organization to achieve organizational change.

In later years, Devanna et al. [16] and Brockbank [11] brought the discussion on the HR role to one about the operational and strategic activities in the organization. According to Devanna et al. [16], the role of the HR department in the organization is divided into three levels: strategic, managerial and operational. The operational level encompasses the routine operational functions, whereas the managerial level is more about managing matters as such the development and retention of employees. In explaining the roles at the different levels, much emphasis was placed on the strategic level. They claimed that the effectiveness of the HR role depends on those functions at the strategic level which are meeting the needs of the business and organization as a whole. Brockbank [11] however divided the HR role into four categories: operationally reactive, operationally proactive, strategically reactive and strategically proactive. Operationally reactive describes those administrative activities under the HR functions such as recruitment and benefits management. Operationally proactive describes the activities of the HR department that can result in them improving their service standards, such as reengineering work processes. Strategically reactive is when the HR department is expected to include business strategy as part of their strategy, but in order to be strategically proactive they are expected to forecast for the future and to create an environment that encourages creativity and innovation. Based on this model, it is said that $\mathrm{HR}$ has a competitive advantage if they are strategically proactive. This provides further evidence from the literature that organizations will perform better when they have an HR department that supports them to achieve a competitive advantage [17].

The various discussions of the HR role bring us to the question of how the HR department is actually playing this strategic role that has been given so much emphasis in the literature. It is a common belief that employees are the most important asset in the organization. In a more interesting perspective, however, Belcourt [18] believes that HR practices are more important than employees in the organization, because current employees may resign and new employees will be hired, but HR practices remain. Does this have any meaning for the HR department? Nevertheless, regardless of whether employees or HR practices are more important, the HR department is expected to play a more strategic role than ever before. Due to the rapidly changing nature of the business, they are expected to be involved strategically in the organization. The devolution of the HR functions to the line managers is said to enable the HR department to focus more on strategic issues [19] even though earlier research proved that was not the case [20] and [21].

Discussion of the strategic involvement of HR has mainly focused on the integration of strategic planning and the involvement of HR in decision making in the organization. Tyson [22] believes that aligning HR's strategic planning with the strategic planning of the organization is an important factor in strategic HR. Thus according to Hiley [23], those involved in the strategic planning of HR must be both proactive and reactive in shaping HR strategies to support the overall strategies of the organization. In decision making, Laabs [24] believes that the opportunity to be elected to the board of directors should be taken by HR professionals, in order to understand better the direction of the organization. This is because the value of HR functions is believed to be dependent upon their integration with different areas of the organization [12]. Since different departments have different objectives, it requires the HR department to "think strategically and creatively" [25] (p.13).

The above-mentioned literature has explained the different roles of HR and the expectation that the HR department will be involved strategically in the organization. Most of the literature, however, relates to the private sector. Moreover, very little research in this area has taken place in HEIs [26] and [27]. Therefore this study will focus on the question of how HR departments in HEIs fulfill their role. The next section will discuss the methods used in this study.

\section{Methodology}

In order to explore the role of HR departments in HEIs, two universities were chosen: one in Malaysia (Uni1) and one in Denmark (Uni2). Since the main objective of this study is to explore HR roles, a case study approach was applied because it helps in understanding the complexity of the HR functions in both organizations. It is impossible to gain an in-depth understanding by using surveys. According to Flyvberg in Seal et al. [28], a case study should be used to understand complex issues. Interview guidelines were prepared for the sessions with all interviewees. The questions in the interview only acted as a guide for the researcher. Interview questions were constructed based on the criteria in Human Resource Role-Assessment Survey by Ulrich and Conner [9]. The assessment was then used to analyze the data. Three groups of people were interviewed: HR directors, HR managers and HR officers. These groups have very close interactions within the 
HR department, thus understanding each of their functions in the department is crucial to understanding the whole department. In total, twenty-one interviews were conducted.

The university in Malaysia (Uni1) is an engineering-based university that has approximately 21,500 students enrolled. Uni1 consisted of 14 institutes and several administrative departments. The HR department in Uni1, which after this will be referred to as HR Uni1, is responsible for managing 5,178 staff, comprising 2,005 academic staff and 3,173 non-academic staff.

The university in Denmark (Uni2) is one of the top universities in the country in the areas of technology and natural sciences. They had a total of 4,502 employees, comprising 1,311 academic staff and 3,191 non-academic staff, and 7,200 students enrolled. The HR department in this university will be referred to as HR Uni2 in the next section.

\section{FINDINGS}

This study shows that both HR departments are aware of the need to be involved strategically in the organization. This impression was given as they spoke about the objectives of the HR department:

- Our objective is to support the university in achieving its target (Director, HR Uni1).

- The focus of the HR department is to support the institutes in achieving their goals by HR tools and project...we have to listen, to ask and to find out (Director, HR Uni2).

However, they have different approaches to role fulfillment. Both HR departments are playing the administrative expert role prominently in their organizations. HR Uni1, however, has more involvement in every work process and almost all of the HR functions in the university are handled by the HR department. Institutes and departments in Uni1 are only responsible for the routine functions of HR, such as salary, attendance and preparing documents related to HR matters for approval by the HR department. For example, in the recruitment and selection process, HR Uni1 is involved at almost every stage and the recruitment can only proceed when the top management of the university has endorsed the decision of the recruitment committee. This is different from the practice in HR Uni2. In Uni2, most of the HR functions are delivered at the institute level. The recruitment process, for example, is done at the institute level. This means that the institutes in Uni2 have the power to recruit new staff, as long as they know they have the budget to pay the salary.

- Each institute has its own budget; they hire or spend their money as they agreed upon with the board of directors (Director, HR Uni2).

- The head of the institute is actually their own director deciding a lot of stuff (Manager2, HR Uni2).

Both HR departments were found to be very concerned about the standard of their service. HR Uni1, for example, had engaged themselves in quality programs such as ISO to increase the efficiency of their department. HR Uni2, however, chose to analyze the yearly survey that they conducted to improve their work processes and also to resolve any issues concerning the service of the HR department. This is what they said about this:

The quality programs are important. ISO for example, is important because we have our customer charter. If there is no customer charter, how can we know what our standards of service are? It is a tool for us to improve our service (Director, HR Uni1).

What the institutes think of our way of working is actually the most important (Director, HR Uni2).

Both universities were found to be actively involved in collaboration and dissemination of their expertise in the international arena. As a result, there has been an increase in the number of international staff in both universities. However, the study shows that HR Uni1 does not really play the role of employee champion, despite the fact that the increased number of international staff is part of the university's target.

- No one really cares about the welfare of these international staff at the faculty (Manager1, HR Uni1).

- The university does seem concerned about the lack of infrastructure for the international staff (Manager2, HR Uni1).

It is different in HR Uni2, where they have a unit called the International Faculty Service (IFS) that handles the welfare of the international staff. The IFS even organizes induction sessions for the new international staff about living in Denmark. During the interviews they even informed me that they plan to hire another staff member to take charge of helping international staff to find accommodation.

- Accomodation is something that we don't look into right now, but we proposed to hire one more officer to look into the accomodation (Manager2, HR Uni2).

The study also reveals that both HR Uni1 and HR Uni2 play a strategic role in the organization. As we can see from the objectives mentioned in the earlier part of the discussion, it has been shown that they are fully aware of their role as strategic partner in the organization. In addition, both HR departments are also aligning their strategic planning to the strategic planning of the universities. Their approaches to developing those strategies, however, are different. HR Uni1 takes a top down approach in which they adopt the strategic plan of the university, whereas HR Uni2 emphasizes the need to support the strategic plans of the institutes and the university as a whole. They also involve all their staff in the strategic planning. In addition, the study shows that strategic contributions are given so much attention that the effectiveness and credibility of the HR department in Uni1 is measured according to whether or not the HR department is able to achieve $90 \%$ of the target Key Performance Indicators (KPIs) of the department. Although this is only the perception of the HR director, it conveys how important it is for them to help the university achieves its targets. The HR department in Uni1 has a very close relationship with the top management. They act as the information provider to the top management in making decisions related to the human resources of the university. Thus emphasis is placed on producing accurate and timely information for the top management. The HR department in Uni2, however, has a different approach to the strategic role. Because many functions of HR are taking place at the institute level, they have created a section called HR Partner to support and give advice to the institutes. The main 
function of this section is to be an intermediary between the HR department and the institutes. The establishment of this section is mainly to ensure the continuous support and the smooth running of the HR functions at the institute level.

We try to get close communication between the partners (HR partners) and the institutes about HR or the strategy on hiring and firing or reorganizing things in the institutes (Director, HR Uni2).

- One of the primary thing about the role is being able to talk to the directors at the institutes (Officer2, HR Uni2).

All the efforts mentioned here, such as the aligning of the HR strategic plan to the strategic plan of the university, the involvement in the decision making process and the support given to the institutes shows the strategic involvement of the HR departments in HEIs.

The change agent role, however, is almost absent in HEIs. In HR Uni1 there is no discussion of evidence that might facilitate change in the university. HR Uni2, however, were engaged in a project they called the employer branding project, where they tried to promote the university as a good place to work for non-academic staff. This is because the university is already a well known place among scientific communities but the HR department believes that recruiting the most qualified and best candidates for non-academic or non-scientific positions is also important to assist the university in achieving its target. Although their efforts are recognized by the top management of the university, nevertheless the top management are at the same time quite skeptical about the project because of its focus on non-academic positions.

- They are a bit afraid because they think the scientific employees will think it is a bit weird that we have to put so much focus on and resources into a project for the administrative staff, although they know that they are very much dependent on them (Manager2, HR Uni2).

In general, the study shows that HR departments in HEIs do fulfil the roles mentioned by Ulrich, especially the administrative expert and strategic roles. Nevertheless there are still roles that are played minimally, such as the employee champion and change agent roles, especially in HR Uni1 in Malaysia.

\section{DISCUSSION AND CONCLUSION}

This study has revealed how HR departments in HEIs fulfill their roles. HR Uni1 was found to lack the roles of employee champion and change agent. Although this was quite shocking for an HR department that works closely with the top management, it is not an isolated case. The same result was found by McDermott and Keating [28] where the HR departments in the health organizations in their study were not involved in the strategic activities and change in the organization. A study carried out at a UK university by Edgley and Huisman [26] also shows a similar result to this study, whereby the HR department does not play a prominent role in the change process. It is an awkward situation for the HR department that believes they are in a strategic position but at the same time are not fulfilling the change agent role. Is the absence of the change agent role in HR departments in
HEIS due to the different contexts of the organizations, which are naturally different from those in the private sector? Or is it because of less emphasis or demand from the top management of universities? Or is it because of a lack of knowledge of the role among HR professionals in HEIs? It is suggested that future research explores this aspect of the HR department and the change agent role in HEIs.

The study also offers findings on the centralization and decentralization of the HR functions. At HR Uni1 in Malaysia, it is very obvious that they practice the centralization of the HR functions. Almost all of the functions are taken care of by the HR department. Only certain functions are carried out by the institutes. This is different to the HR department in Uni2, where they decentralize most of the HR functions to the institutes and departments. This in line with result found by Hoogendoorn and Brewster [29] that claimed Denmark is the highest in rank of devolvement of HR functions to the line managers. Findings from Meyer and Hammerschmid [30] also confirmed that Scandinavian countries prefer more decentralized HR. Thus this may address certain issues arising in the study, for example it is possible that the roles of employee champion and change agent in HR Uni2 have been taken care of at the institute level. It also explains why most of the decisions in the HR department in Uni1, even concerning the recruitment and selection process, are made by the top management. It also explains the focus of HR Uni1 on meeting the demands of the top management. According to Tessema et al. [31] most organizations practice both centralization and decentralization. In this study, however, it is obvious that the HR department in Uni2 in Denmark is more inclined to decentralize its HR functions compared to the HR department in Uni1 in Malaysia, where most of its functions are centralized.

This study shows that HR departments in HEIs are involved strategically in the organization. However, they have to fulfill more prominent roles, especially the change agent role as it brings added value to the HR department in the organization. Thus this study has opened an avenue for future researchers to investigate whether HR professionals in HEIs have the same understanding of the concept of the change agent role as that which is described in the current literature.

\section{REFERENCES}

[1] J. H. Dulebohn, G. R. Ferris, and J. T. Stodd, "The history and evolution of human resource management" Handbook of Human Management, G. R. Ferris, S. D. Rosen, and D. T. Barnum, Eds. Blackwell Publishers, 1995.

[2] J. J. Jamrog and M. H. Overholt, "Building a strategic HR function continuing the evolution," Human Resource Planning., vol. 27, no. 1, pp. 51-62, 2004.

[3] M. Patrick and L. Hartmann, "Human resource management in australia: Prospects for the twenty-first century," International Journal of Manpower, vol. 22, no. 3, pp. 198-206, 2001.

[4] A. Yeung and W. Brockbank, "Lower cost, higher value: Human resource function in transformation," Human Resource Planning., vol 17, no. 3, pp. 1-16, 1994.

[5] C. J. Ehrlich, "Human resource management: A changing script for a changing world," Human Resource Management., vol. 36, no. 1, pp. 85-89, 1997.

[6] S. Tyson, "Why HR management will never be the same again," Personnel Today., pp. 13, 2007.

[7] A. Yeung, M. Warner, and C. Rowley, "Growth and globalization: evolution of human resource management practices in Asia," Human Resource Management, vol. 47, no. 1, pp. 1-13, 2008. 
[8] W. M. Mothershell, M. L. Moore, J. K. Ford, and J. Farrell, "Revitalizing human resource management in state government: Moving from transactional to transformational $\mathrm{hr}$ professionals in the state of Michigan," Public Personnel Management., vol. 37, no. 1, pp. 77-97, 2008.

[9] D. Ulrich, Human Resource Champions: The Next Agenda for Adding Value and Delivering Results, Boston, MA: Harvard Business School Press, 1997.

[10] R. W. Beatty and C .E. Schneier, "New HR roles to impact organizational performance: From "Partners" to "Players"," Human Resource Management., vol. 36, no. 1, pp. 29-37, 1997.

[11] W. Brockbank, "If HR were really strategically proactive: Present and future directions. In HR's contribution to competitive advantage," Human Resource Management., vol. 38, no. 4, pp. 337-352, 1999.

[12] D. Buyens and A. De Vos, "Perceptions of the value of the HR function," Human Resource Management Journal., vol. 11, no. 3, pp. 29-37, 2001.

[13] M. Langbert and H. Friedman, "Continuous Improvement in the History of Human Resource Management," Management Decision., vol. 40 , no. 8 , pp. 782-787, 2002

[14] C. Truss, "Continuity and change: The role of the HR function in the modern public sector," Public Administration., vol. 86, no. 4, pp. 1071-1088, 2008.

[15] J. H. Marler, "Making human resources strategic by going to the Net: Reality or myth?" The International Journal of Human Resource Management., vol. 20, no. 3, pp. 515-527, 2009.

[16] M. A. Devanna, C. J. Fombrun, and N. M. Tichy, "A framework for strategic human resource management," in Human Resource Management: Critical Perspectives on Business and Management, $\mathrm{M}$. Poole, Ed., London: Routledge, 1999.

[17] D. P. Lepak and S. A. Snell, "Virtual HR: Strategic human resource management in the $21^{\text {st }}$ century," Human Resource Management Review., vol. 8, no. 3, pp. 215-234, 1998

[18] M. Belcourt, "HR's field of dreams: Lessons from the ball diamond can help HR transform from transactional to strategic," Canadian HR Reporter., vol. 22, no. 15, pp. 23, 2009.

[19] M. Harris and A. Raviv, "Organization design," Management Science., vol. 48, no. 7, pp. 852-865, 2002.

[20] I. Cunningham and J. Hyman, "Devolving human resource responsibilities to the line: Beginning of the end or a new beginning for personnel?" Personnel Review., vol. 28, no. 1/2, pp. 9-27, 1999.

[21] P. Budhwar and Y. A. Debrah, "Future research on human resource management systems in Asia," Asia Pacific Journal Management., vol. 26, pp. 197-218, 2009

[22] S. Tyson, "The changing nature of human resource management," in The Changing Pattern of Human Resource Management, F. Analoui. Ed., England: Ashgate Publishing Limited, 2002, pp. 1-11.

[23] M. Hiley, "Corporate strategy in the ASEAN Region: Human resource management dimension," in Changing Pattern of Human Resource
Management, F. Analoui. Ed., England: Ashgate Publishing Limited, 2002. pp. 1-11.

[24] J. J. Laabs, "HR adds value to board of directors," Personnel Journal., vol. 71, no. 11, pp. 12-15, 1992.

[25] R. Pomeranz, "The evolution of human resource directors' responsibilities," The CPA Journal., vol. 79, no. 7, pp. 12-13, 2009.

[26] C. P. Edgley and J. Huisman, "The role of the HR department in organizational change in a British university," Journal of Organizational Change Management, vol. 24, no. 5, pp. 610-625, 2011.

[27] F. Qadeer, R. Rehman, M. Ahmad, and M. Shafique, "Does ownership of education institute influence its HRM patterns? The case of pakistan," International Journal of Business and Management, vol. 6, no. 10, pp. 230-241, 2011

[28] B. Flyvbjerg, "Five misunderstandings about case-study research," in Qualitative Research Practice, C. Seal, G. Gobo, J. Gubrium, and D. Silverman, Eds., California: Thousand Oaks, 2004, pp. 420-434.

[29] J. Hoogendoorn and C. Brewster, "Human resource aspects: decentralization and devolution," Personnel Review., vol. 21, no. 1, pp. 4-11, 1993.

[30] R. E. Meyer and G. Hammerschmid, "The degree of decentralization and individual decision making in central government human resource management: A european comparative perspective," Public Administration., vol. 88, no. 2, pp. 455-478, 2010.

[31] M. T. Tessema, J. L. Soeters, and A. Ngoma, "Decentralization of HR functions: Lesson from the singapore civil service," Review of Public Personnel Administration., vol. 29, no. 2, pp. 168-188, 2009.

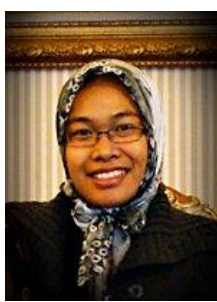

Azlineer Sarip is a senior lecturer at the Faculty of Management, Universiti Teknologi Malaysia, Johor Bahru Campus. She obtained her Ph.D. in Social Science from Roskilde University, Denmark in 2012. She was HR practitioner and has working experience in both private and public sectors. She is with UTM for more than 10 years and currently active in research related to Strategic Human Resource Management .

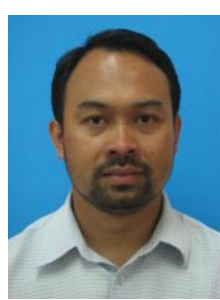

Mohamad Abdillah Royo is a lecturer at the Faculty of Education, Universiti Teknologi Malaysia, Johor Bahru Campus. He is with UTM for more than 6 years and currently pursuing his Ph.D. in Entrepeneurial Learning. 